Nunt. Antiquus, Belo Horizonte, v. 14, n. 1, p. 233-254, 2018

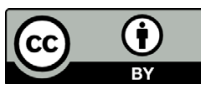

\title{
Agaton no Banquete: um prelúdio à filosofia
}

\section{Agathon in the Symposium: A Prelude to Philosophy}

\author{
Matheus Abreu Pamplona \\ Universidade Federal do Pará, Belém, Pará / Brasil \\ matheusjcap@gmail.com
}

Resumo: Neste artigo, procuro indicar como o elogio de Agaton (194e-197e), ao contrário do que comumente vemos ser sustentado pela maior parte dos intérpretes do Banquete, pode ser lido como uma espécie de prelúdio às concepções posteriormente defendidas por Sócrates e Diotima. Com o intuito de comprovar minha hipótese, primeiramente questiono um dos motivos que levou a tradição exegética a rejeitar o discurso do tragediógrafo como fonte de opiniões verdadeiras sobre o amor, a saber, a associação feita pelo próprio Sócrates entre o elogio de Agaton e a retórica de Górgias. Em um segundo momento, defendo que o conteúdo do encômio do poeta trágico, apesar do estilo gorgiânico por ele adotado, alinha-se em muitos pontos àquilo que vemos Sócrates sustentar em seu próprio discurso em louvor a Erōs.

Palavras-chave: Agaton; Sócrates; filosofia.

Abstract: In this article I will try to show how Agathon's speech (194e-197e) can be read as a sort of prelude to the conceptions later sustained by Socrates and Diotima, contrary to what we commonly see being defended by most of the interpreters of the Symposiun. In order to prove my point I will first question one of the reasons that led scholars to reject the tragedian's speech as a source of right opinions about love: the association made by Socrates between Agathon's discourse and Gorgias' rhetoric. Secondly, I will argue that the content of the poet's speech is in many ways aligned with what we see Socrates maintaining in his own speech in praise of Erōs, despite the Gorgianic style adopted by him.

Keywords: Agathon; Socrates; Philosophy. 


\section{Introdução}

$\mathrm{Na}$ sequência de elogios que compõem o Banquete, somos confrontados com diversas perspectivas acerca do que seria o amorquem ele é e quais seriam os seus benefícios para os seres humanos. Pausânias, Fedro, Erixímaco, Aristófanes, Sócrates, Diotima, e ainda Alcibíades, todos eles, podemos dizer, apresentam seus discursos em homenagem a Erōs sob a ótica de diferentes ramos do saber, tais como o mito, a sofística, a medicina, a poesia, a retórica, a religião, a filosofia e etc. Neste quadro, costuma-se ressaltar o ponto de vista de Sócrates em oposição a todos aqueles que o antecedem, sob a alegação de que seria ele o único responsável por veicular as concepções filosóficas de Platão. ${ }^{1}$ Contra este lugar-comum, adotamos quanto à leitura do Banquete um tipo de postura que procura conceder a todos os elogios uma participação ativa na construção de uma teoria filosófica sobre Erōs. Se, no entanto, por questões de economia, não podemos aqui apresentar razões que justifiquem nossa posição quanto ao demais elogios, gostaríamos de fornecer ao menos alguns argumentos que comprovem nossa hipótese de leitura em relação ao discurso de Agaton (194e-197e). Entendemos que, ao contrário do que é comumente defendido pela tradição exegética do Banquete, ${ }^{2}$ o encômio do tragediógrafo, para além de todo o componente retórico que lhe é próprio, é aquele que mais se aproxima do de Sócrates quanto à importância das premissas que são apresentadas.

\section{Agaton, o "gorgiânico"}

Antes propriamente de indicarmos os pontos de continuidade que julgamos encontrar entre os elogios de Sócrates e Agaton, convém que tentemos compreender o porquê de o elogio do poeta trágico receber ainda hoje avaliações majoritariamente negativas por parte da crítica

\footnotetext{
${ }^{1}$ O locus classicus deste tipo de interpretação é Robin (1908, p. 9).

${ }^{2}$ Além do já citado Robin, Bury (1909, p. xxxvi) e Dover (1980, p. 123) também são representantes deste tipo de posicionamento. O caso de Guthrie (1975, p. 380-396) nos parece ainda mais grave, uma vez que em seu comentário ao Banquete, o elogio de Agaton sequer é mencionado.
} 
especializada. ${ }^{3} \mathrm{Um}$ dos fatores que certamente contribuem para este tipo de avaliação é a associação entre o estilo utilizado pelo tragediógrafo e a retórica de Górgias, relação que é reconhecida e denunciada pelo próprio Sócrates - "com efeito, vinha-me à mente o discurso de Górgias. [...] Temia que, concluindo, Agaton em seu discurso enviasse ao meu a cabeça de Górgias, terrível orador, e de mim mesmo me fizesse uma pedra, sem voz"4 (198c) - e que é brilhantemente exemplificada também por Agaton em sua peroração (197d-e).

A influência de Górgias no Agaton do Banquete não se faz simplesmente notar a partir do estilo utilizado pelo tragediógrafo na composição de seu elogio, ainda que este ponto seja reconhecidamente importante. ${ }^{5}$ Mais do que isso, poderíamos ainda afirmar que a alusão à retórica do sofista no discurso do poeta é mais do que uma sugestão, uma vez que as linhas finais proferidas por Agaton podem inclusive ser tomadas como uma referência literal ao Elogio de Helena. Se Agaton caracteriza o seu discurso "em parte jocoso, em parte [...] discretamente sério" (197e) (tà mèn paidiâs, tà dè spoudês metrías), Górgias finaliza sua peça afirmando que desejou "apresentar por escrito o discurso de Helena como um elogio e, no que concerne, como um jogo (paígnion)" (21). ${ }^{6}$

Há pouco falávamos que um dos possíveis motivos para a leitura enviesada do elogio de Agaton seria o tom sofístico que o encômio do poeta inevitavelmente assumiria. Este estado de coisas é sintomático. De acordo com Hunter (2004, p. 74), a persistente associação, feita por

\footnotetext{
${ }^{3}$ Um exemplo ilustrativo de uma posição recente, mas que ao mesmo tempo reproduz os preconceitos disseminados pela tradição, pode ser encontrado em Brisson (2006, p. 246), para quem o elogio de Agaton seria vazio mesmo que magnificamente construído. De modo semelhante vemos Allen (1991, p. 41) afirmar que "Agathon's speech and by implication the others, is a specimen of flattery, aiming at pleasure but indifferent to truth". ${ }^{4}$ Para fins de citação do Banquete, utilizamos a tradução de J. Cavalcante de Souza (2012).

${ }^{5}$ Principalmente caso levemos em consideração a importância de Górgias no desenvolvimento estilístico da prosa grega dos séculos V e IV a.C. Esta questão é particularmente reconhecida por Dover (1980, p. 123) em seu comentário à peroração de Agaton.

${ }^{6}$ Para fins de citação do Elogio de Helena, de Górgias, utilizamos a tradução de Dinucci (2009).
} 
Platão, de Górgias com um tipo de retórica que pouco se preocuparia com a verdade, aponta para o caminho que deveríamos tomar ao lermos o que o Agaton do Banquete tem a dizer sobre Erōs. Se, por exemplo, entendermos o Elogio de Helena enquanto um modelo notório de uma retórica epidítica, na qual o que estaria em jogo seria bem menos uma preocupação com a verdade do que a própria habilidade do retor em persuadir os seus ouvintes, então parece um pouco mais claro do porquê tomar-se, afinal, o discurso de Agaton como uma peça de retórica, vazio na sua essência, uma vez que, a princípio, partilharia dos mesmos motivos que animaram Górgias quando este escreveu o Elogio. ${ }^{7}$ Ora, o grande problema deste tipo de interpretação é que ela depende necessariamente que tomemos os escritos de Górgias apenas enquanto um exercício retórico. Ainda que este componente seja indiscutivelmente importante, a partir do momento em que assumimos um tipo de posicionamento que admite que as peças do sofista são muito mais do que um simples jogo de palavras, e que constituem tratados a respeito da natureza do pensamento, da linguagem e da realidade e que, portanto, o motivo que os anima seria um motivo também de natureza filosófica, então fica evidente que a simples associação entre Górgias com quem quer que seja não deveria constituir em si mesmo um problema que desabonasse as pretensões daquele que visse no sofista um modelo a ser seguido. ${ }^{8}$

Ao tomar os sofistas como adversários e ao fazer o discurso do tragediógrafo parecer aos olhos de Sócrates um símile dos discursos gorgianos, o próprio Platão (se intencionalmente ou não, jamais poderemos afirmar) parece ter selado o destino do elogio de Agaton perante os olhos da tradição. De qualquer forma, assumimos a hipótese de que o lugar-comum das leituras a respeito do discurso de Agaton é equivocado. Procuraremos agora explicar o porquê de crermos nisso,

\footnotetext{
${ }^{7}$ Opinião que é compartilhada, por exemplo, por Bury (1909, p. xxxv): “in his portrait of the nature of Eros - his youth, beauty, suppleness of form and delicacy of complexion - Agathon does little more than formulate the conventional traits of the god as depicted in poetry and art. His attempts to deduce these attributes are mere paidiá (197e), pieces of sophistical word-play".

${ }^{8}$ Para uma reapreciação das doutrinas de Górgias ver especialmente Kerferd (2003, p. 135-188) e Untersteiner (2012, 163-297).
} 
indicando como o encômio do poeta trágico pode ser lido como que apresentando contribuições positivas ao discurso socrático.

\section{Agaton, o "socrático"}

Voltando-nos ao discurso de Agaton, a primeira coisa que salta aos olhos é a crítica empreendida pelo poeta ao modo como até então os outros simposiastas conduziram os seus respectivos elogios. Reclama, por exemplo, de que até aquele momento todos os que o precederam "não eram o deus que elogiavam, mas os homens, que felicitavam pelos bens de que o deus lhes é causador; qual porém é a sua natureza, em virtude da qual ele fez tais dons, ninguém o disse" (195a). Se Pausânias já havia feito referência à maneira adequada de se proferir elogios (180d), será Agaton, contudo, o primeiro que não apenas tentará colocar efetivamente em prática esta exigência, mas que estabelecerá um tipo de metodologia no que concerne à determinação de um objeto que será, ela própria, como veremos, socrática: "ora, a única maneira correta de qualquer elogio a qualquer um é, no discurso, explicar em virtude de que natureza vem a ser causa de tais efeitos aquele de quem se estiver falando" (195a).

Esta questão de ordem metodológica foi particularmente realçada por Allen (1991, p. 41-42). Se, por um lado, este intérprete partilha das opiniões comuns que enxergam no elogio de Agaton uma peça de natureza meramente retórica, que não visaria outra coisa senão provocar prazer naqueles que a escutassem e que permaneceria, portanto, indiferente à verdade, por outro, reconhece que a metodologia empregada pelo poeta coaduna-se com o mesmo tipo de exigência feita por Sócrates em outros diálogos, particularmente no Ménon (71b), no que concerne à necessidade de se definir primeiramente em que consistiria determinado objeto ( $t i$ esti), para que apenas num segundo momento possamos indagar que tipo de objeto ele é (hopoîón gé ti). Esta exigência definicional é do mesmo modo afirmada no Banquete, não por Sócrates primeiramente, mas por Agaton, ao sustentar que, no que concerne a Erōs, seria necessário primeiro que estabelecêssemos quem ele é (hopoîós tis), para que só posteriormente passássemos a investigar quais seriam, afinal, as suas obras (tà érga autoû). 
É particularmente surpreendente, quanto a isto, notar como Allen (1991, p. 41-42), mesmo reconhecendo que a metodologia empregada por Agaton é uma metodologia socrática, ainda possa tratar o discurso do tragediógrafo como definitivamente negligente quanto à verdade. Contra isto, poderíamos, não obstante, nos perguntar se o próprio reconhecimento de Sócrates em 199c de que Agaton havia procedido corretamente quando sugeriu "que primeiro se devia mostrar o próprio Amor, qual sua natureza e depois as suas obras" (légon hóti prôton mèn déoi autòn epideîxai hopoîós tís estin ho Érōs, histeron dè tà érga autôu), bem como a admissão em 201d-e de que antes de conhecer Diotima ele próprio, Sócrates, pensava tal qual Agaton, partilhando inclusive dos mesmos "pré-conceitos", não constituem um motivo suficientemente razoável para aceitarmos a possibilidade de que o elogio de Agaton possa de fato apontar para uma espécie de entendimento minimamente correto acerca do que seja Erōs. Não que com isso não reconheçamos o caráter, quanto a determinados aspectos, deficitário do elogio do tragediógrafo. Este aspecto é inclusive admitido por Sócrates, especialmente no élenkhos a que submete o poeta (199c-201c). Contudo, pretendemos apenas indicar que, de modo geral, o discurso proferido por Agaton possui uma espécie de potencialidade, e que, consequentemente, acaba por contribuir significativamente na construção de uma concepção filosófica sobre o amor, ${ }^{9}$ algo que também parece ser reconhecido por Sócrates, mesmo que não explicitamente (201d-e; 205b-d).

\footnotetext{
${ }^{9}$ Este ponto é especialmente reconhecido por Sheffield (2006, p. 33), que atua na contramão da maior parte dos intérpretes que se dedicam a comentar o elogio de Agaton: "Agathon did not propose a viable account of eros' nature (as a beautiful god) on which to base his account of its beneficial effects. But this is not to say that Agathon's speech is nonsense. Socrates goes on to show that Agathon is right that eros has some relationship both to beauty and to divinity; he is muddled about the precise nature of those relationships. This is a muddle to which Socrates himself, apparently, was subject, before he met the mysterious Diotima (201e3-7). Indeed, Socrates presents his own account as a repeat performance of this meeting because he used to say things similar to those said by Agathon. He goes on to show how his own account developed on the basis of things agreed between himself and Agathon, and, on that previous occasion, Diotima and the young Socrates (201d5)".
} 
Toda esta potencialidade a que nos referimos há pouco é reconhecida, por exemplo, por Sedley (2006, p. 47-52), para quem Agaton deveria ser tomado como um conduíte socrático e que o conteúdo do seu elogio seria, ele próprio, "sub-socrático", uma vez que as concepções defendidas pelo poeta permaneceriam muito próximas daquelas defendidas pelo filósofo. Se as opiniões de Sócrates se provaram frutíferas a ponto de serem rasuradas por Diotima e ainda assim conduzirem o filósofo no caminho de um entendimento adequado das coisas relativas ao amor (tà erotiká), e se Sócrates naquele momento compartilhava exatamente das mesmas opiniões defendidas por Agaton, então é de se esperar que a mesma potencialidade encontrada em Sócrates e que foi atualizada pelos ensinamentos de Diotima possa igualmente ser encontrada nas ideias do tragediógrafo.

Após definir qual a metodologia correta a ser adotada em um encômio, Agaton passa então a louvar propriamente a divindade. Segundo a natureza, o Erōs de Agaton, dentre todos os deuses, é não apenas o mais feliz, mas também o mais belo e o melhor. A justificativa para tal é que, sendo o mais novo dentre as divindades, Erōs foge da velhice, e assim o faz, pois, uma vez jovem, é necessariamente entre os jovens que estabelecerá morada (195a-b).

É importante notar como a um só tempo Agaton procura rasurar teses importantes sustentadas por dois de seus antecessores, notadamente Fedro e Erixímaco. Este procedimento de revisão alinha-se àquele de ordem definicional, de determinação da natureza do deus, procedimento que, segundo o próprio Agaton, não foi levado a cabo adequadamente por aqueles que the precederam. Se Fedro havia sustentado que Erōs era o mais antigo dos deuses e, justamente por causa desta antiguidade é que provinham aos seres humanos os maiores benefícios possíveis (178b), Erixímaco defendera que o dissemelhante ama e deseja o dissemelhante. Contra o médico e parafraseando um trecho da Odisseia (XVII, 218), Agaton defenderá exatamente o contrário, que "o semelhante sempre do semelhante se aproxima" (195b). Ainda que esta seja uma premissa que será em parte rejeitada por Sócrates no momento do élenkhos, ela é de todo modo necessária para o estabelecimento de um dos argumentos 
decisivos de todo o diálogo e que assume no ensinamento de Diotima uma importância capital, qual seja, o de que Erōs/erōs (seja a divindade ou a afecção) de alguma forma relaciona-se com o belo (197b; 201a). Na lógica desenvolvida por Agaton, Erōs tem como objeto o belo exatamente porque ele próprio é belo e, mais que isso, somente porque belo é que justamente pode ser causa dos maiores benefícios para os seres humanos (196a-b; 197b-c).

Esta conclusão, que à primeira vista parece trivial, possui, na verdade, um substrato metafísico importante. De acordo com Sedley (2006, p. 54-58), Agaton, mais do que qualquer outro simposiasta, parece consciente do funcionamento de relações de causalidade e, consequentemente, da necessidade, para que estas relações sejam estabelecidas, da presença de semelhança. Se Fedro - citado nominalmente pelo tragediógrafo -, ao derivar da antiguidade de Erōs a possível origem dos benefícios que lhes são provenientes, havia demonstrado pouca familiaridade com este tipo de raciocínio, Agaton, ao contrário, ao estabelecer um vínculo de semelhança entre Erōs, seus objetos e os atributos de que é causa, faz eco a uma das mais importantes teses de todo o pensamento platônico do período da maturidade, tese que vemos ser desenvolvida especialmente no último argumento acerca da imortalidade da alma no Fédon (102a-107a). Dentre outras coisas, neste argumento vemos ser defendida a tese de que se uma coisa - um corpo qualquer - possui um predicado acidentalmente - o "quente", por exemplo -, isto se dá graças à presença naquela coisa de algo que é essencialmente quente - o fogo. Do mesmo modo podemos dizer de um animal que está momentaneamente vivo graças à presença nele de algo que é permanentemente vivo, i.e., a alma.

Notemos que no Fédon é dito que estes portadores primários desempenham uma função causal; eles são causa da presença daqueles atributos ou predicados nos portadores secundários. Se com Sócrates esta lógica será aplicada para explicar o funcionamento do desejo em nós, antes disso, no entanto, veremos Agaton insistir neste mesmo ponto, ao afirmar que "primeiramente por ser em si mesmo o mais belo e o melhor, depois é que é para os outros a causa de tantos outros bens" 
(197c). Temos, pois, que Erōs, essencialmente belo e bom, é causa de toda a beleza e de toda bondade. ${ }^{10}$

Se para os outros simposiastas Erōs associava-se simplesmente a um verbo, Agaton, ao contrário, o tornará senão o próprio sujeito e causa do amor. Como notou Sedley (2006, p. 56-57) mais uma vez e, antes dele, Allen (1966, p. 460) já o havia feito, a própria noção trazida à tona por Sócrates de que Erōs carece de beleza e bondade só se torna viável à medida em que reconhecemos que o sujeito do amor não são "pessoas" que amam, mas o amor em si mesmo (erōs) que é causa de todo o amar. Esta mudança de perspectiva operada por Sócrates, de tornar Erōs um intermediário, só é possível graças à senda aberta por Agaton, que corretamente soube distinguir entre causa e efeito. Aliás, o reconhecimento desta nuance permite que muitas das aparentes inconsistências presentes nas premissas que Sócrates lança mão no élenkhos de Agaton possam ser esclarecidas. Quanto a isto, Sedley (2006, p. 56-57) tem razão quando insiste que no élenkhos dirigido por Sócrates, amantes, entendidos enquanto "pessoas", podem muito bem possuir coisas belas e boas e ainda sim permanecerem "amantes", isto porque esta beleza que por eles é possuída pode se manifestar em diferentes modos: é plenamente possível para alguém possuir beleza corporal, por exemplo, ao mesmo tempo em que é carente de outras formas de beleza, como a beleza que se manifesta nas obras e nas ocupações. À medida em que, no entanto, despersonalizamos o sujeito do amor, podemos mais facilmente admitir que o desejo ou o amor em si mesmo que reside nos seres humanos, que é o que efetivamente os leva a amar, este sim, em hipótese alguma

\footnotetext{
${ }^{10}$ Sedley (2006, p. 55) resume toda a sua argumentação nos seguintes termos: "this observes the causal principle, so prominent in the Phaedo, that a cause must itself possess the same property as it brings about in something else: it is only hot things that can make you hot, for example. It is at the same time a prime example of the further refinement of that principle, regularly credited to Plato in antiquity, that 'the cause is greater than the effect': whatever makes you hot has to be not only hot, but hotter than it could ever make you. And it is precisely those twin causal principles that underlie the metaphysical thesis to which I have already referred: if you desire something, your doing so is secondary to, and is caused by, the presence in you of the relevant desire, itself the primary subject of the desiring".
} 
pode possuir permanentemente os predicados de que é carente pois, caso contrário, jamais poderia ser causa de todo amor e de todo desejo, uma vez que desejo implica necessariamente privação. Que Sócrates e Agaton divergem quanto à natureza de Erōs, não podemos negar. Entretanto, acreditamos que é possível reconciliar os dois elogios na medida em que reconhecemos que tanto Sócrates quanto o tragediógrafo concordariam em admitir que Erōs, enquanto sujeito e causa do amor, é o portador primário dos predicados que comunica àqueles em que se faz presente.

Pensemos, por exemplo, nos adjetivos que Agaton atribui a Erōs. É frequentemente notado por intérpretes que em seu elogio Agaton confere ao deus do amor as mesmas características que usualmente se atribuiriam ao erốmenos no contexto da pederastia e, ao descrevê-lo como belo, jovem e delicado, o poeta estaria na verdade descrevendo a si próprio, de modo que seu elogio seria, na verdade, um autoelogio. ${ }^{11}$ Contudo, mais do que um exercício narcísico, poderíamos sustentar que, na verdade, este tipo de postura respeita a uma motivação também de ordem metodológica e conceitual. Se, como vimos, Agaton tem consciência do papel que a semelhança assume numa relação causal, então é coerente que, na lógica de seu discurso, o tragediógrafo faça com que a beleza e a bondade, que são marcas essenciais do deus, também sejam comunicadas àqueles que por ele são tocados. Quando Sócrates tomar a palavra e expuser aquilo que ouviu de Diotima, veremos este mesmo princípio (que foi primeiramente exposto no élenkhos) ser transposto, porém em termos psicológicos. Acerca disso, Sedley (2006, p. 57-58) é mais uma vez preciso: o amor, assim como todas as formas de desejo - e aí inclui-se a própria filosofia -, tem sua origem numa espécie de privação que é, ela própria, criativa, ao invés de simplesmente tê-la a partir da possessão efetiva daquilo que, porventura, se possa aspirar. Se os predicados essenciais de Erōs giram

${ }^{11}$ Este argumento é sustentado, por exemplo, por Hunter (2004, p. 71): "In the Protagoras Socrates describes the adolescent Agathon as 'of a fine (kaloskagathos) nature and of very fine (kalos) looks' ( $315 \mathrm{~d} 8$-e1) and, though probably around thirty in $416 \mathrm{BC}$, he still plays the role of beautiful object of desire at his own symposium. His speech, moreover, depicts Eros as an idealized version of the 'model erômenos', namely, Agathon himself in his prime - young, beautiful, soft, and creative". 
em torno de sua natureza dinâmica, sempre a oscilar entre estados de aporía e euporía, poderíamos então sustentar que ao fazer-se presente em nós, Erōs nos tornaria, por semelhança, portadores contingenciais dos predicados que ele próprio possui essencialmente. Tendo isto em mente, poderíamos nos perguntar: seria, afinal, por acaso que podemos reconhecer na personalidade do próprio Sócrates muitos dos predicados que são atribuídos a Erōs por Diotima? Tal como Erōs, não estaria Sócrates - pobre, sujo, descalço e malvestido - também "longe de ser delicado e belo, como a maioria imagina" (203c-d)? Se, como sustentamos até aqui, dentre todos os demais discursantes é Agaton o único a exibir uma compreensão sobre a causalidade que poderíamos denominar propriamente de "platônica", por que então hesitamos em aceitar a hipótese de que, ao estabelecer uma espécie de homologia entre os atributos de Erōs e daqueles que são por ele inspirados, ao invés de simplesmente proferir um autoelogio a partir da idealização da natureza do erốmenos no interior de uma relação homoerótica, o poeta esteja, ao invés, exibindo um tipo de entendimento que poderíamos igualmente denominar de "platônico", na medida em que veremos este procedimento ser igualmente adotado por Sócrates, que tomará como modelo não mais a imagem do erómenos, porém a do erastếs?

Para ilustrar este ponto, lembremos apenas que Agaton, ao sustentar que Erōs é delicado, assim o faz sob o argumento de que o deus do amor não caminha sobre o que é duro, e isto inclui tanto o solo quanto as cabeças dos seres humanos. Ao contrário - respeitando mais uma vez o princípio anteriormente estabelecido de que "semelhante atrai semelhante" -, Agaton fará Erōs habitar e mover-se por sobre aquilo de que mais brando existe, os caráteres e as almas (en gàr éthesi kaì psykhaîs); mas não em todas, somente naquelas cujas constituições coadunam-se com a do próprio deus (195e). Ao brincar com os predicados de Erōs numa lógica que parece até mesmo banal, podemos novamente defender que Agaton chega a uma conclusão cujas consequências se farão notar de modo significativo no discurso de Sócrates. Se momentos antes Aristófanes havia transformado Erōs em um desejo próprio da alma (192d), desejo que é responsável inclusive por determinar o destino dos seres humanos, afinal, nossa promessa de felicidade futura depende 
exatamente da possibilidade de satisfação deste desejo, Agaton - ainda que continue tratando Erōs como uma divindade e não como uma afecção propriamente dita, como havia sido o caso do comediógrafo -, ao tornar a alma o local onde Erōs reside, não apenas fará dela a sede das paixões, como também abrirá espaço para pensarmos numa fecundidade que lhe é própria, algo que se tornará mais claro quando o tragediógrafo começar a discorrer a respeito da sabedoria do deus.

Lembremos como Pausânias, ao estabelecer uma diferença entre dois tipos de Erōs, um popular e outro celeste, advogara em favor deste último argumentado que este tipo de amor era nobre justamente porque aqueles que o praticavam voltavam suas atenções a um objeto constante, a alma (183e-184a). Diferentemente do amor dos corpos que, efêmero, exatamente porque o corpo também o é, o amor que se direciona ao caráter excelente (éthous chrestô̂) é duradouro porque funde-se (syntakeís) com o que é constante (nonímou). Neste ponto de sua argumentação Pausânias equipara "alma" e éthos com o intuito de mostrar que o télos do bom amor deve ser a excelência. Dito isto, podemos perceber que algo muito similar é posto em prática por Agaton. Como notou Casertano (2013, p. 21, n. 31), a fórmula en gàr èthesi kaì psykhaîs utilizada pelo tragediógrafo para justificar a delicadeza de Erōs pode ser lida quase como uma hendíadis. Caso sejamos efetivamente autorizados por este tipo de leitura, chegaremos à conclusão de que Agaton, assim como Pausânias fizera anteriormente, torna o éthos senão que a própria alma de cada ser humano. Este é sem dúvida um passo significativo para a ruptura com determinado tipo de mentalidade. Ao dar este passo, Agaton afasta-se em certa medida da própria tradição mítica; tradição que, não nos esqueçamos, fornecia aos tragediógrafos o material a partir do qual suas próprias obras poderiam ser compostas.

Ao tornar as almas e os caracteres a morada de Erōs e ao fazer da alma senão o próprio ethos humano, Agaton parece antecipar, ainda que de modo tímido, um ponto fundamental de toda a doutrina de Diotima no Banquete, mas que veremos ser mais explicitamente desenvolvido no Fedro e no livro IX da República: a caracterização da natureza da alma como essencialmente erótica. 
Outra questão interessante para a qual gostaríamos de chamar atenção diz respeito ao tratamento dispensado por Agaton, um poeta, à própria tradição poética na qual ele se inseriria. Para tal, podemos perguntar se, ao questionar a antiguidade de Erōs defendida por Fedro, Agaton não estaria também questionando as próprias autoridades das quais Fedro se serviu para defender sua tese. Ao afirmar que "as questões entre os deuses, de que falam Hesíodo e Parmênides, foi por Necessidade e não por Amor que ocorreram, se é verdade o que aqueles diziam" (195c), Agaton parece duvidar se as palavras proferidas pelos poetas são sempre verdadeiras e, consequentemente, também parece pôr sob suspeita as próprias genealogias por eles compostas. Caso aceitemos esta perspectiva - e caso também nos seja permitido fazer um exercício de imaginação -, Agaton poderia, na verdade, estar sugerindo algo como: Hesíodo e Parmênides, como se sabe, fizeram Erōs ocupar em suas genealogias um lugar decisivo ao lado dos primeiros deuses, o que, não por acaso, seria indicativo de sua antiguidade. No entanto, se isto fosse verdade, os sequestros, castrações, e tantos outros tipos de violência de que são testemunho, não poderiam ter ocorrido, uma vez que, estando Erōs entre os deuses, o que ali se instalaria não seria outra coisa senão sentimentos de amizade e de paz. Portanto, tudo aquilo que os poetas nos contam acerca das violentas disputas entre os imortais só poderia ter ocorrido, se é que de fato ocorreu, por obra da Necessidade, jamais de Erōs, que sequer havia nascido. Eis a prova, por conseguinte, da sua juventude. ${ }^{12}$ Dito isto, gostaríamos ainda de chamar atenção para mais dois pontos. Em primeiro lugar, devemos salientar que esta posição de distanciamento em relação à tradição poética assumida pelo Agaton platônico não deveria em absoluto nos surpreender. Se crermos naquilo que Aristóteles nos diz na Poética (IX, 1451b-19-26) a respeito da relação entre a poesia e a história, e a utilização dos mitos da tradição pelos poetas trágicos, perceberemos que este é, inclusive, um tipo de postura rastreável até mesmo às práticas do Agaton histórico.

\footnotetext{
${ }^{12}$ Para uma leitura diferente deste ponto, mas cuja conclusão em boa parte coaduna-se com a nossa própria, ver Sedley (2006, p. 67-69).
} 
Como podemos notar, orientando-nos pelo testemunho de Aristóteles, este posicionamento crítico que Agaton parece assumir perante a tradição poética não é algo que teria sido arbitrariamente fabricado por Platão, embora certamente ele se valha deste traço e o manipule a ponto de conceder, seja a um episódio ou a um personagem particular da história grega, uma função filosófica dentro do seu sistema. Isto é recorrente nos Diálogos, e o Banquete não constitui exceção. De qualquer forma, o reconhecimento deste tratamento crítico dispensado à tradição poética por parte tanto do Agaton platônico quanto do histórico permite-nos que passemos ao segundo ponto que nos propusemos a destacar. Acreditamos que o modo como Agaton encara a tradição poética que lhe precede alinha-se a uma postura que é, ela própria, também socrático-platônica. Basta que lembremos, por exemplo, do livro II da República, onde vemos Sócrates - de modo semelhante a Agaton no Banquete - pôr sob suspeita aquilo que os poetas dizem a respeito dos deuses (377e-378a).

Após discorrer sobre a beleza de Erōs, Agaton passa então a argumentar em favor da bondade do deus. Neste ponto, é importante que notemos que aquele princípio de semelhança que liga causa e efeito a que aludimos há pouco também será utilizado pelo tragediógrafo para descrever as virtudes de Erōs - especialmente sua sabedoria -, indicando assim por que deveríamos considerá-lo como bom. Para tal, o poeta atribui a Erōs as quatro virtudes cardinais da justiça (dikaiosýnēe), moderação (sōphrosýnē), coragem (andreía) e sabedoria (sophía) (196b-197b), as mesmas virtudes cuja presença no livro IV da República (427e-428a) é dita imprescindível caso queiramos fundar uma cidade perfeita.

Se o recurso às virtudes cardinais pela parte do tragediógrafo constitui ou não um indicativo do caráter genuinamente socrático do seu discurso, quanto a isto muitos divergem. ${ }^{13}$ Contudo, poder-se-ia

\footnotetext{
${ }^{13}$ Bury (1909, p. 77), por exemplo, acredita que um traço significativamente platônico como este dificilmente seria posto na boca de alguém como Agaton. Sedley (2006, p. 59), ao contrário, defende mais uma vez que se Platão deliberadamente colocou no discurso de Agaton um elemento tão importante como este, é porque deveríamos levar a sério o que poeta tem a nos dizer sobre isso.
} 
ainda sustentar que por mais que Agaton refira-se às virtudes cardinais, o modo como ele as entende e os argumentos que utiliza para sustentar seu ponto de vista podem muito bem diferir substancialmente daqueles do Sócrates platônico. ${ }^{14}$ À primeira vista, este parece ser justamente o caso quando voltamos nossa atenção aos argumentos dados por Agaton na caracterização da excelência de Erōs. Mas, como veremos, mesmo que isto seja válido para as virtudes da justiça, da coragem, e da moderação, quanto à sabedoria, por exemplo, o tratamento a ela dispensado pelo poeta é inclusive reconciliável com teses que são reconhecidamente socráticas.

Agaton começa a sua descrição da excelência do deus afirmando que $E r \bar{s} s$ "não comete nem sofre injustiça, nem de um deus ou contra um deus, nem de um homem ou contra um homem" (196b). Além do que, não provoca nem sofre coerção. Se algo o afeta, não é por violência; quando age sobre os outros, tampouco o faz mediante o uso da força. Ao contrário, todos que servem a Erōs o fazem voluntariamente, afinal, como insiste Agaton, Erōs e violência não se misturam (196c).

Além da justiça, Erōs toma parte grandemente também na moderação (pròs dè tếi dikaiosýnéi sophrosýnēs pleístēs metékhei). Se a moderação consiste no domínio (tò krateîn) dos prazeres e paixões, e se nenhum prazer é mais forte do que o amor, então Erōs exerce controle sobre todas as demais afecções. O caráter excepcionalmente temperante de Erōs reside justamente na sua capacidade de subjugar prazeres e paixões, mesmo que ele próprio seja uma espécie de prazer (196c).

Quanto à tentativa de demonstração da coragem de Erōs, Agaton lança mão de um expediente semelhante àquele por ele utilizado quando da exposição da moderação do deus, qual seja, tratar a virtude - neste caso, a coragem - enquanto uma relação de "poder". Recorrendo agora à tradição mitopoética, veremos Agaton desenvolver a sua lógica nos seguintes termos: se Ares é tido como o mais corajoso dentre os deuses e se, no entanto, ao jugo de Erōs se submete (aqui mais uma vez Agaton

${ }^{14}$ Esta é a posição defendida, por exemplo, por Nehemas e Woodruff (1989, p. 34, n. 4), para quem o tratamento das virtudes cardinais pela parte de Agaton é baseada numa série de confusões: "justice he equates wrongly with nonviolence, courage and moderation with power, wisdom with technical skill". 
recorre ao vocabulário do kratéō), será então forçoso admitir que é ele, Erōs, e não Ares a quem devemos considerar o mais corajoso de todos (196d). Ao poder de Erōs nem mesmo o deus da guerra consegue opor resistência.

Até aqui, os argumentos oferecidos por Agaton para justificar a atribuição das virtudes cardinais a Erōs não parecem coadunar-se com aquilo que Sócrates defenderia em outros diálogos. Lembremos mais uma vez que ao fim de sua participação, Agaton considerará o seu próprio elogio como "em parte jocoso, em parte [...] discretamente sério" (197e). O tom jocoso com o qual Agaton tece seus argumentos e o abuso na apresentação de possíveis provas que, de todo modo, carecem de rigor lógico, fizeram com que Sedley (2006, p. 60), por exemplo, enxergasse nesta parte do discurso do tragediógrafo exatamente aquele momento espirituoso, do qual o próprio Agaton parecia ter consciência. Não deveríamos ainda, neste caso, considerar o mea culpa do poeta como um atenuante e assim, de uma vez por todas, livrá-lo das acusações que lhes são injustamente imputadas? Por que deveríamos exigir rigor argumentativo de alguém que abertamente declina desta pretensão?

De qualquer forma, se não podemos encontrar na análise destas três primeiras virtudes o elo que nos permitiria associar mais uma vez a exposição de Agaton às linhas do pensamento socrático, ${ }^{15}$ quando nos voltarmos ao exame da sophía de Erōs feito pelo poeta, poderemos então indicar mais claramente de que modo o tratamento desta questão por Agaton adequa-se plenamente ao projeto posto em curso por Sócrates em seu elogio, principalmente no que diz respeito à consideração da atividade erótica - e aqui seja ela qual for - como essencialmente criativa.

O primeiro passo dado por Agaton na exposição da sabedoria de Erōs consiste na sobreposição feita pelo poeta das noções de tékhnē

\footnotetext{
${ }^{15}$ Nehemas e Woodruff (1989, p. 34, n. 36) criticam, por exemplo, o entendimento de Agaton acerca do que seria a sophrosyne, escancarando assim a distância que separa as concepções de Agaton e aquelas defendidas por Platão: "Plato and Aristotle generally contrast sophrosune as a virtue with 'self-control': the person with sophrosune is naturally well-tempered in every way and so does not need to control himself, or hold himself back. Here Agathon plays on the idea of self-control, losing the sense in which sophrosune is a real excellence of character".
} 
e sophía. O que à primeira vista parece uma redução (do ponto de vista filosófico, é claro), i.e., tornar a sabedoria equivalente a uma habilidade técnica, na verdade conduz a argumentação a uma dimensão até então não atingida, principalmente se levarmos em consideração o modo como as outras três virtudes foram anteriormente tratadas por Agaton. Seguindo a linha estabelecida por Erixímaco, que havia tomado como objeto de seu elogio não somente o deus, mas também a sua própria arte, Agaton, tal como ele próprio o é, fará de Erōs um poeta, mas não qualquer um, e sim um "sábio, tanto que a outro ele o faz"; ademais, continua afirmando que "qualquer um em todo caso torna-se poeta, "mesmo que antes seja estranho às Musas', desde que lhe toque o Amor" (196e).

A lógica aqui desenvolvida por Agaton faz-nos lembrar mais uma vez daquele conhecimento de relações causais que atribuímos ao poeta e sobre o qual há pouco falávamos. Se Erōs é capaz de transmitir aos outros a sua própria habilidade, fazendo com que todos aqueles que por ele sejam tocados transformem-se em poetas (poiētè̀s gígnetai), então é necessário que ele próprio seja um poiêtès. Isto é bem mais do que um simples jogo de palavras e antecipa a própria distensão semântica operada por Diotima em sua tentativa de demonstrar como Erōs pode e deve ser entendido para além de sua conotação sexual. Este movimento de alargamento de sentido tem início à medida que Agaton expande a próprio esfera de atuação de Erōs. Por certo que a sabedoria do deus do amor, enquanto poeta que é, possa se manifestar mais prementemente nas criações artísticas, esta virtude, contudo, a elas não se restringe, senão que até mesmo as ultrapassa, a ponto de Agaton perguntar se "na criação [poíésis] dos animais todos, quem contestará que não é sabedoria do Amor, pela qual nascem e crescem todos os animais?" (197a). A ideia de tornar a sabedoria de Erōs uma sabedoria "poietica" (produtora) permite a Agaton estender os seus efeitos para além dos limites impostos por uma tékhnē específica, neste caso, a poesia. Isto já havia sido feito anteriormente por Erixímaco. Alinhando-se a esta proposta, Agaton pode então apresentar um escopo relativamente extenso (não tão extenso quanto o de Diotima, é verdade) dentro do qual a sophía essencialmente criativa de $E r \bar{s} s$ se revela. 
Partindo da poesia em stricto sensu (196e), passando pela geração da vida no mundo animal (197a), Agaton nos mostra que até mesmo na profissão dos artífices (tekhnōn dèmiourgían) esta sabedoria específica de Erōs se manifesta (197a). Para ilustrar este ponto, o tragediógrafo sugere ainda que, porque movidos pelo amor (erōs) e pelo desejo (epithymía), é que os deuses puderam criar as suas respectivas tékhnai: Apolo, a técnica de manejar o arco, a adivinhação e a medicina; as Musas, as artes em geral; Hefesto, a arte de manipulação do bronze; Atena, a tecelagem; e até mesmo Zeus, a arte de governar (197a-b). Quanto a esta última manifestação é curioso notarmos como Agaton retoma uma ideia que havia aparecido primeiramente no elogio de Fedro e que também será mais adiante retomada por Diotima. Aqueles que são eroticamente inspirados, i.e., que possuem Erōs como mestre (didáskalos), não apenas se tornam "produtores" (poiētai), mas atraem para si celebridade e glória. Ainda que os termos aqui empregados por Agaton difiram daqueles utilizados por Diotima em 208d, a ideia por eles compartilhada é semelhante: a de que Erōs de algum modo conduz à transcendência (enquanto Diotima lança mão de termos como dóxa e kléos para explicitar como a philotimía é também uma espécie de manifestação erótica; Agaton utiliza ellogímos e phanòs para indicar como aqueles que são por Erōs tocados saem da obscuridade e atraem para si reconhecimento). Talvez a diferença aqui esteja no modo menos rigoroso com que Agaton apresenta os seus argumentos. Enquanto a exposição (altamente sofisticada, diga-se de passagem) de Diotima acerca da etiologia de Erōs abandona o plano mítico e caminha em direção a uma justificação de ordem psicológica (Erōs, o daímon, dá lugar a erōs, a afecção), a de Agaton, por outro lado, mantém-se num nível que poderíamos chamar de "intuitivo".

É claro que, como vimos, as "intuições" de Agaton contém o seu próprio valor e devem consequentemente ser levadas plenamente a sério. Uma prova disso - tanto desta diferença no que diz respeito à forma de exposição e à utilização de argumentos justificados por cada um deles, quanto à questão do valor dos insights do poeta trágico - nos é dada pelo próprio modo como ambos, Agaton de um lado, Sócrates e Diotima de outro, constroem a relação entre Erōs e poíésis, i.e., entre desejo e criatividade. Ao tornar Erōs um poeta e fazer com que ele 
inspire qualquer tipo de produção, não somente artística, mas também manual, Agaton opera um duplo alargamento, não apenas do sentido do termo amor, mas também do de produção. E aí reside a novidade: erōs e poíesis são de tal modo distendidos a ponto de compreenderem dentro de suas esferas não apenas aquele sentido elementar que cada uma delas até então possuía - desejo sexual em se tratando de erōs; poesia no que diz respeito à poíesis - mas sim todo um novo gênero cuja marca distintiva é a própria noção de criatividade. De erōs como expressão da paixão erótica, sexual acima de tudo, a erōs como manifestando toda e qualquer espécie de desejo de natureza criativa; de poíesis como produção artística determinada à poíésis como manifestando toda e qualquer espécie de atividade criativa.

Após discorrer acerca da natureza daimônica de Erōs (202a-204c) e estabelecer a quais objetos ele se dirigiria, Diotima passa então a expor que tipo de benefício ele proporcionaria aos seres humanos (204d). Após fazer Sócrates assentir que aqueles que amam as coisas boas amam, na verdade, possuí-las, a sacerdotisa pôde enfim estabelecer que aquilo a que todos os seres humanos buscam por meio da possessão destas tagathá é exatamente a própria felicidade (eudaimonía). Se este desejo e este amor (pelas coisas belas e boas) é comum a todos os seres humanos - afinal, todos desejam ser felizes (205a) -, então por que, pergunta Diotima, denominamos de "amantes" apenas algumas destas pessoas? É a partir deste ponto que Diotima põe em curso um processo de revisão semântica. O problema, nos esclarece a sacerdotisa, é que: "destacamos do amor um certo aspecto e, aplicando-lhe o nome do todo, chamamo-lo de amor, enquanto para outros aspectos servimo-nos de outros nomes" (205b). Para elucidar o seu ponto de vista, Diotima leva às últimas consequências aquilo que Agaton havia apenas "intuitivamente" sugerido:

Sabes que "poesia" é algo de múltiplo; pois toda causa de qualquer coisa passar do não-ser ao ser é "poesia", de modo que as confecções de todas as artes são "poesias", e todos os seus artesãos poetas. [...]

Todavia - continuou ela - tu sabes que estes não são denominados poetas, mas têm outros nomes, 
enquanto de toda a "poesia" uma única parcela foi destacada, a que se refere à música e aos versos, e com o nome do todo é denominada. Poesia é com efeito só isso que se chama, e os que têm essa parte da poesia, poetas. [...]

Pois assim também é com o Amor. Em geral, todo esse desejo do que é bom e de ser feliz, eis que é "o supremo e insidioso Amor, para todo homem", no entanto, enquanto uns, porque se voltam para ele por vários outros caminhos, ou pela riqueza ou pelo amor à ginástica ou à sabedoria, nem se diz que amam nem que são amantes, outros ao contrário, procedendo e empenhando-se numa só forma, detêm o nome do todo, de amor, de amar e de amantes. (PLATÃO, Banquete, 205c-d).

Foi a partir desta teorização acerca de "gêneros" e "espécies" que Diotima pôde em última instância desvincular Erōs de todas aquelas concepções "comuns" apresentadas pelos outros simposiastas e concederlhe, durante o seu ensinamento, um sentido radicalmente novo: o amor como filosofia. Este processo de transposição dos sentidos de Erōs, por mais que encontre nos discursos de Sócrates e Diotima a sua forma mais bem-acabada, é algo que sem dúvida alguma permeia o Banquete como um todo, mas que no discurso de Agaton é ainda mais flagrante. Durante toda a cadeia encomiástica vemos ser postuladas teses que de uma forma ou de outra reaparecerão no discurso de Sócrates (algumas destas teses serão aceitas passivamente, enquanto outras serão submetidas a um exame crítico contundente). ${ }^{16}$ Ao fim do diálogo, perceberemos

\footnotetext{
${ }^{16}$ Sheffield (2006, p. 37) faz um inventário de todas estas teses: "this brief survey of Socrates' speech should suffice to show that there is a great deal of continuity between the philosophical account and the previous speeches. We have seen many cases where things said by the previous speakers are taken up as they stand. Consider, for example, the following claims: that eros desisres what it lacks (191a5-6); that eros is of beauty (197b8); that eros for the soul is more valuable than eros for the body (184a1); that good things arise from the love of beautiful things (197b8-9); that eros aims at virtue (178c5-6, 179a8, 180b7-8, 188d5-6, 178c5-6, 179a8, d1-2, 180b7-8, 184d7, 185b5,
} 
que há bem mais continuidades entre o discurso socrático e os outros seis elogios - e o discurso de Agaton não constitui exceção -, do que propriamente rupturas. Se as rupturas existem, e é claro que elas de fato existem, isto também se insere no próprio movimento dialético de recondução do olhar, no qual a descoberta da unidade só é possível mediante a presença daquilo que é múltiplo. O resultado deste processo de absorção, crítica, e ressignificação - de reconhecimento de diferenças acima de tudo - é o que, no final das contas, poderemos efetivamente chamar de "amor platônico".

\section{Referências}

ALLEN, R. E. A Note on the Elenchus of Agathon: Symposium 199c-201c. The Monist, Oxford, v. 50, n. 3, p. 460-463, 1966.

ARISTÓTELES. Poética. Tradução, prefácio, introdução, comentário e apêndices de Eudoro de Souza. 7. ed. Lisboa: Imprensa Nacional - Casa da Moeda, 2003.

BRISSON, L. Agathon, Pausanias, and Diotima in Plato's Symposium. In: LESHER, J.; NAILS, D.; SHEFFIELD, F. Plato 's Symposium: Issues in Interpretation and Reception. Washington, D.C.: Center for Hellenic Studies, 2006. p. 229-251.

CASERTANO, G. Em busca da alma no Banquete. Kairos: Revista de Filosofia \& Ciência, Lisboa, v. 7, p. 13-33, 2013.

DINUCCI, A. Apresentação e tradução do Elogio de Helena de Górgias de Leotinos. ETHICA, Rio de Janeiro, v. 16, n. 2, p. 201-212, 2009.

GUTHRIE, W. K. C. A History of Greek Philosophy. v. 4: Plato: The Man and his Dialogues - Earlier Period. Cambridge: Cambridge University Press, 1975.

188d4-9, 196d4-e6), the good (188d5) and happiness (180b7, 188d8, 193d5, 194e6, 195a5); that eros must be governed by knowledge (188d1-2; cf. 184d1-e1); that is has some intimate relationship to phronesis (182b7-c2, 184d1), episteme (187c4-5), sophia (196d5-6), and that eros brings together the human and the divine (188d8-9). The inclusion of such views in an account that professes to 'speak the truth' suggests that these are indeed "nuggets of truth". 
HUNTER, R. Plato's Symposium. Oxford: Oxford University Press: 2004. (Oxford Approaches to Classical Literature).

KERFERD, G. B. O movimento sofista. Tradução de Margarida Oliva. São Paulo: Edições Loyola, 2013.

PLATÃO. A República. Tradução de Ana Lia Amaral de Almeida Prado. 2. ed. São Paulo: Martins Fontes, 2014.

PLATÃO. Fédon. Tradução de Carlos Alberto Nunes. 3. ed. Belém: EDUFPA, 2011.

PLATÃO. O Banquete. Tradução, introdução e notas de José Cavalcante de Souza. 7. ed. São Paulo: DIFEL, 2012.

PLATO. Symposium. Edited by Sir Kenneth Dover. Cambridge: Cambridge University Press, 1980.

PLATO. Symposium. Translated, with introduction and notes, by A. Nehamas and P. Woodruff. Indianapolis: Hackett Publishing Company, 1989.

PLATO. The Dialogues of Plato. v. 2: The Symposium. Translated by R. E. Allen. New Haven: Yale University Press, 1991.

PLATO. The Symposium of Plato. Edited with introduction, critical notes and commentary by R. G. Bury. London: Simpkin, Marshall and Co., 1909.

ROBIN, L. La théorie platonicienne de l'amour. Paris: Félix Alcan, 1908.

SEDLEY, D. The Speech of Agathon in Plato's Symposium. In: REIS, B. The Virtuous Life in Greek Ethics. Cambridge: Cambridge University Press, 2006. cap. 3, p. 47-69.

SHEFFIELD, F. C. C. Plato's Symposium: The Ethics of Desire. Oxford: Oxford University Press, 2006.

UNTERSTEINER, M. A obra dos sofistas: uma interpretação filosófica. Tradução de Renato Ambrósio. São Paulo: Paulus, 2012.

Recebido em: 15 de janeiro de 2018. Aprovado em: 1ํ de março de 2018. 